\title{
Development of a Robust UPLC Method for Simultaneous Determination of a Novel Combination of Sofosbuvir and Daclatasvir in Human Plasma: Clinical Application to Therapeutic Drug Monitoring
}

\author{
Naser F. Al-Tannak, ${ }^{1}$ Ahmed Hemdan, ${ }^{2,3}$ and Maya S. Eissa $\mathbb{D}^{4}$ \\ ${ }^{1}$ Department of Pharmaceutical Chemistry, Faculty of Pharmacy, Kuwait University, AlJabriyah, Kuwait \\ ${ }^{2}$ Department of Pharmaceutical Analytical Chemistry, Faculty of Pharmacy, Ahram Canadian University, Giza, Egypt \\ ${ }^{3}$ Institute of Clinical Chemistry, University Medical Center Hamburg-Eppendorf(UKE), Martinistraße 52, 20246 Hamburg, Germany \\ ${ }^{4}$ Department of Pharmaceutical Analytical Chemistry, Faculty of Pharmacy, Egyptian Russian University, Cairo, Egypt \\ Correspondence should be addressed to Maya S. Eissa; maya-shaaban@hotmail.com
}

Received 28 May 2018; Accepted 2 October 2018; Published 21 October 2018

Academic Editor: Samuel Carda-Broch

Copyright ( 2018 Naser F. Al-Tannak et al. This is an open access article distributed under the Creative Commons Attribution License, which permits unrestricted use, distribution, and reproduction in any medium, provided the original work is properly cited.

\begin{abstract}
A rapid and selective UPLC-DAD method was developed and validated for simultaneous analysis of the novel two-drug combination Darvon $i^{\circledR}$ for the treatment of HCV: Sofosbuvir (SF)/Daclatasvir (DC) in human plasma using Ledipasvir as internal standard (IS) where the extraction process was conducted using automated SPE. Although the analysis of the combination after concomitant oral intake of two tablets of SF and DC individually was reported in literature, yet simultaneous analysis of this new combination in human plasma after a single oral dose was not previously reported. The adopted chromatographic separation was achieved on Waters ${ }^{\circledR}$ Acquity UPLC BEH $\mathrm{C}_{18}$ column $(2.1 \times 50 \mathrm{~mm}, 1.7 \mu \mathrm{m})$ as a stationary phase using isocratic elution using a mobile phase system of ammonium formate $(\mathrm{pH} 3.5 ; 5 \mathrm{mM})$ and acetonitrile $(60: 40 \mathrm{v} / \mathrm{v})$ pumped at a flow rate of $0.2 \mathrm{~mL} \cdot \mathrm{min}^{-1}$. The UV detection was carried out at $261 \mathrm{~nm}$ for SF and $318 \mathrm{~nm}$ for DC and IS. SF was eluted at 1.123 min while DC was eluted at $3.179 \mathrm{~min}$. The proposed chromatographic method was validated in accordance with guidelines of FDA for bioanalytical method validation. A linear range was achieved in the range of 25-6400 and 50-12800 ng.mL $\mathrm{m}^{-1}$ for SF and DC, respectively. The proposed UPLC-DAD method was found to be accurate with \% bias ranging between -10.0-7.2 for SF and -6.9-8.0 for DC. Also it was proved to be precise with \% CV for intraday precision ranging between 3.8-9.6 for SF and 2.8-9.2 for DC whereas interday precision ranged between 5.1-9.3 for SF and 3.7-9.1 for DC. Moreover, \% extraction recovery ranged between 90.0-107.2 for SF and 93.1-108.0 for DC using the suggested method. The adopted chromatographic method was successfully applied to the therapeutic drug monitoring of SF and DC in healthy volunteers after the oral intake of one Darvoni ${ }^{\circledR}$ tablet.
\end{abstract}

\section{Introduction}

Infection due to hepatitis $\mathrm{C}$ virus (HCV) is a leading cause for severe chronic liver disease, which can result in progressive liver damage such as cirrhosis and hepatocellular carcinoma. Thus, it is considered to be a great worldwide health problem specifically in Egypt, which has the greatest prevalence of the epidemic problem of HCV in the world in accordance with the reported Egyptian Demographic Health Survey [EDHS] that had reached $14.7 \%$. So prevention of HCV becomes a national priority [1].
The available treatment options for HCV infection until 2011 were restricted to ribavirin with pegylated interferon combination. This drug regimen has limited efficacy, especially in genotype 1 infected patients, and was also accompanied with dangerous side effects [2].

In 2014, the directly acting antivirals were introduced in the market as a new anti-HCV generation. The main goal of these new drug therapies is decreasing the incidence of possible side effects for HCV patients. These powerful drugs encompass Nonnucleoside Inhibitors (NNIs) and Nucleoside 


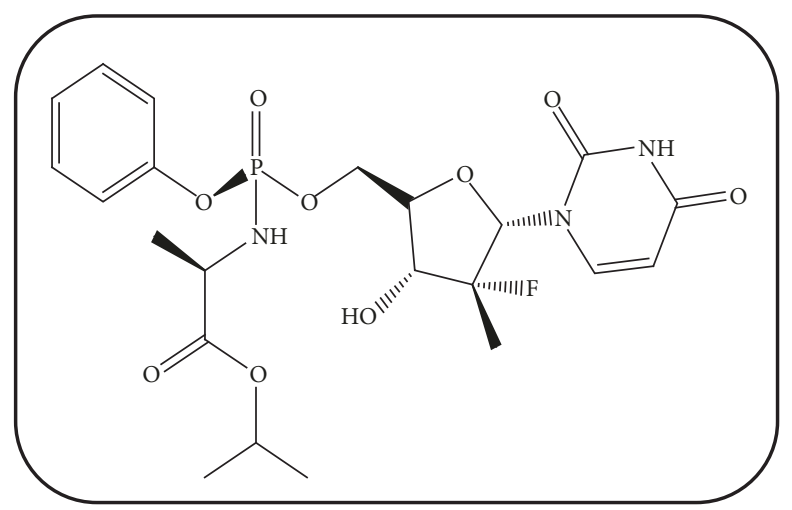

(a)

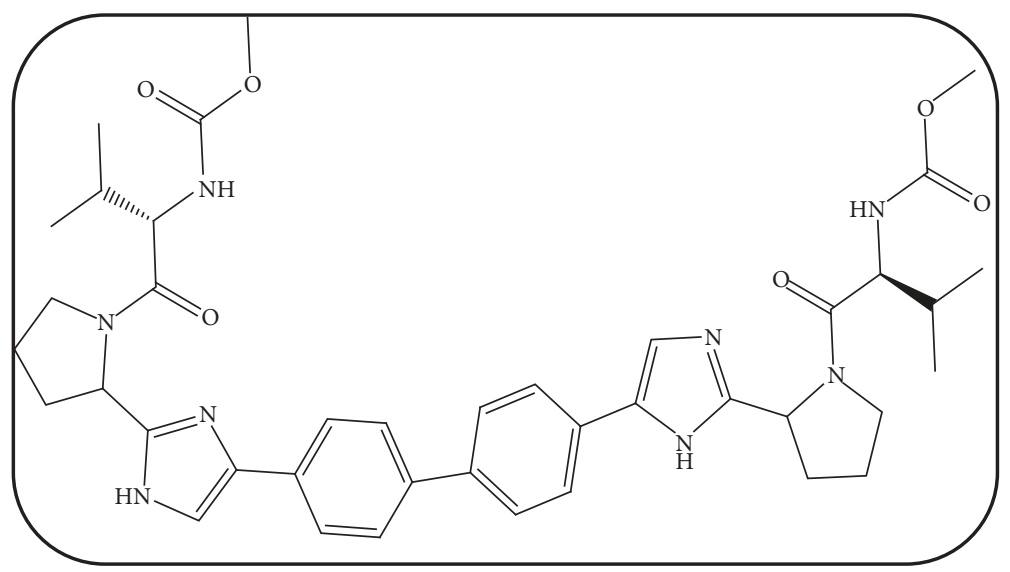

(b)

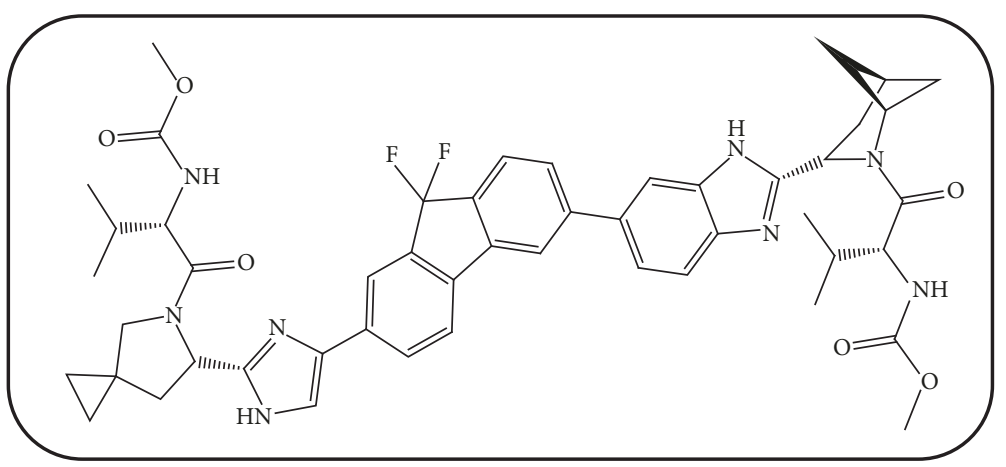

(c)

FIgURE 1: Chemical structure of SF (a), DC (b), and IS (c).

Inhibitors (NIs) of HCV RNA polymerase (NS5A/5B) and Protease Inhibitors (PIs). As shown in Figure 1(a), Sofosbuvir (SF) is the first released drug of the new generation and is an oral NI which is used alone or in combination with pegylated interferon $\propto$ /Ribavirin or with PIs as well as with NNIs (such as Ledipasvir or Daclatasvir) [3]. SF is a white to off-white crystalline solid having a molecular weight of $529.458 \mathrm{~g} / \mathrm{mol}$, with a solubility $\geq 2 \mathrm{mg} / \mathrm{mL}$ across the $\mathrm{pH}$ range of 2-7.7 at $37^{\circ} \mathrm{C}$, and is slightly soluble in water. It has $\log \mathrm{P}$ value $=1.62$ and has two pKa values; $\mathrm{pKal}=9.38$ (amide); $\mathrm{pKa} 2=10.30$ [4].

Daclatasvir (DC) is the first discovered drug as HCV RNA polymerase NS5A replication complex inhibitor [5].
Its chemical structure is presented in Figure 1(b). DC is effective against genotypes 1 and 3 . DC (molecular weight $=$ $738.89 \mathrm{~g} / \mathrm{mol}$ ) is a white to yellow crystalline nonhygroscopic powder. It is freely soluble in water, dimethyl sulfoxide, and methanol; soluble in ethanol (95\%); practically insoluble in dichloromethane, tetrahydrofuran, acetonitrile, acetone, and ethyl acetate. It has $\log \mathrm{P}$ value $=4.67$ and a $\mathrm{pKa}$ value $=11.15$ [6]. DC has illustrated a good safety profile upon concomitant intake with SF [7]. The once-daily oral dose of anti-HCV concomitant drug therapy of SF + DC has shown high rates of sustained virologic response in patients infected with $\mathrm{HCV}$ genotype 1 or 3 and also has been accompanied with better 
therapeutic outcomes [8]. Ledipasvir (IS) is used as internal standard; its chemical structure is presented in Figure 1(c). Ledipasvir is practically insoluble $(<0.1 \mathrm{mg} / \mathrm{mL})$ across the $\mathrm{pH}$ range of 3.0-7.5 and is slightly soluble below pH 2.3 (1.1 $\mathrm{mg} / \mathrm{mL}$ ). It has a molecular weight of $889.018 \mathrm{~g} / \mathrm{mol}$, Log $\mathrm{p}$ value $=3.8$. It has two pKa values: pka1 $=4.0$ and $\mathrm{pka} 2=5.0$. [9]

The increase in number of therapeutic options available for patients suffering $\mathrm{HCV}$ infections introduces a great challenge in the selection and management of HCV treatment. In regard to this, Therapeutic Drug Monitoring (TDM) is considered to be an important tool to assess the efficacy of drug regimen, help the clinicians to adjust the drug dosage, optimize the therapy or switch the treatment regimen, and overcome adverse events or therapeutic failure [10, 11].

Due to the extensive use of the mentioned drugs in combination therapy, the therapeutic drug monitoring of concentrations of SF and DC concentrations in patients undergoing HCV therapy is very important and critical, especially in determining the treatment optimization and the potential of drug interaction.

Therefore, there were several reported methods for SF and/or DC determination in human plasma using HPLC-UV detection [12-14], micellar LC method [15], and LC-MS/MS [16-23].

To the best of our knowledge, the adopted bioanalytical approach in this work will be the solely UPLC-PDA technique first developed for the simultaneous quantification of SF and DC in human plasma with a clinical application to their therapeutic drug monitoring after the oral intake of a coformulated tablet containing SF+DC (Darvoni ${ }^{\circledR}$ recently manufactured by Beacon Pharmaceuticals Limited) instead of the commonly two tablets dosage regimen of each one alone (Sovaldi ${ }^{\circledR}+$ Daklinza $^{\circledR}$ ). In accordance with US Food and Drug Administration (FDA) guidelines [24], the adopted UPLC-DAD method in this work was successfully developed and carefully validated. Also a successful clinical application to the adopted method was also conducted through therapeutic drug monitoring process after the intake of Darvoni ${ }^{\circledR}$ tablet to three healthy volunteers.

\section{Materials and Methods}

2.1. Chemicals and Reagents. Drug standards for SF, DC, and Ledipasvir (IS) were kindly supplied by Memphis Co. for Pharmaceutical and Chemical Industries, Cairo, Egypt, with certified purity of $99.98 \pm 0.421$ for SF, $99.93 \pm 0.231$ for DC, and $99.87 \pm 0.642$ for Ledipasvir. Darvoni film-coated tablets (coformualted with $400 \mathrm{mg}$ SF and $60 \mathrm{mg}$ DC) were purchased from Beacon Pharmaceuticals Limited, Bangladesh. Drug-free human plasma was obtained from Kuwait Blood Bank, Al Jabriyah, Kuwait. HPLC grade acetonitrile and other used chemicals in the adopted method were of analytical grade and obtained from Sigma Aldrich, Dor-set, UK. "In house" HPLC grade water was prepared with a MilliQfilter purchased from Millipore, Watford, UK. Syringe membrane filters $(13 \mathrm{~mm})$ were purchased from kinesis scientific expert, Cambridgeshire, UK. Nylon solvent filters (0.45 um) used for
TABLE 1: Quality control samples for SF and DC.

\begin{tabular}{lcc}
\hline Prepared QC samples (ng.mL $\mathrm{mL}^{-1}$ ) & SF & DC \\
\hline LLOQ & 25 & 50 \\
QL & 50 & 100 \\
QM & 400 & 1600 \\
QH & 3200 & 6400 \\
ULOQ & 6400 & 12800 \\
\hline
\end{tabular}

solvent filtration and Water 20-positions Extraction Manifold with SPE cartridges (Sep-Pak ${ }^{\circledR}$ Vac C18) used for sample preparation were purchased from Water Corporation, Milford, USA. SPE eluates were dried using DRI-BLOCK DB-3 evaporator which was purchased from Techne, Stone, UK.

2.2. Instrumentation and Chromatographic Conditions. Chromatographic separation was achieved using Waters ${ }^{\circledR}$ Acquity UPLC separation module with quaternary Solvent Manager (H-Class), online degasser with autosampler injector, and photodiode array detector coupled with Empower $^{\circledR}$ software for data acquisition (Waters ${ }^{\circledR}$, Milford, USA). Waters ${ }^{\circledR}$ Acquity UPLC BEH $\mathrm{C}_{18}$ column $(2.1 \mathrm{~mm} \times$ $50 \mathrm{~mm}, 1.7 \mu \mathrm{m}$ particle size) was used as the stationary phase for the development of the chromatographic separation, optimization, and method validation. An isocratic elution was conducted using a mobile phase system of $5 \mathrm{mM}$ of ammonium formate in water and acetonitrile $(60: 40 \mathrm{v} / \mathrm{v})$. The flow rate was set at $0.2 \mathrm{~mL} \cdot \mathrm{min}^{-1}$. Column temperature was adjusted at $45^{\circ} \mathrm{C}$ and samples were injected at $2 \mu \mathrm{L}$ injection volume and determined at a wavelength of $261 \mathrm{~nm}$ for SF and $318 \mathrm{~nm}$ for DC and IS.

2.3. Solutions. Due to the possible degradation of DC in solution at high-intensity UV and visible light as previously reported by [25], all the solutions and samples containing DC must be protected from daylight during its preparation, storage, and analysis. Two stock solutions for each of SF and DC were prepared in methanol as $1.0 \mathrm{mg} \cdot \mathrm{mL}^{-1}$. Each stock standard solution was then further diluted with the same solvent to produce working standard solutions at the following concentration levels: $1.25,2.5,5.0,10.0,20.0,80.0,160.0$, and $320.0 \mu \mathrm{g} . \mathrm{mL}^{-1}$ for SF and 2.5, 5.0, 10.0, 20.0, 80.0, 160.0, 320.0, and $640.0 \mu \mathrm{g} . \mathrm{mL}^{-1}$ for DC. Ledipasvir (IS) working standard solution was prepared as $50 \mu \mathrm{g} \cdot \mathrm{mL}^{-1}$ in methanol. Plasma calibration standards were freshly prepared at the following concentration levels: $25,50,100,200,400,1600,3200$, and $6400 \mathrm{ng} \cdot \mathrm{mL}^{-1}$ for SF and 50, 100, 200, 400, 1600, 3200, 6400, and $12800 \mathrm{ng} \cdot \mathrm{mL}^{-1}$ for DC by dilution from their respective working solutions in control human plasma and subjected to subsequent analysis on the same day. The quality control (QC) samples used were subsequently prepared by further dilution of the working standard solutions in human plasma as presented in Table 1 .

2.4. Preparation of Plasma Samples. Sample clean-up was conducted using the following SPE procedure: The cartridges were first preconditioned with acetonitrile $(1 \mathrm{~mL})$ then 
equilibrated by water $(1 \mathrm{~mL})$, in a positive pressure manifold. A volume of $450 \mu \mathrm{L}$ of acetonitrile and a volume of $50 \mu \mathrm{L}$ of IS were added to $500 \mu \mathrm{L}$ of the spiked human plasma samples, vortexed for one min approximately, and then centrifuged at room temperature for $10 \mathrm{~min}$ at $15,000 \mathrm{rpm}$ to permit protein precipitation. Supernatants were then loaded onto SPE cartridges on a 20 position extraction manifold operated under positive vacuum. Then, the cartridges were washed with water $(1 \mathrm{~mL})$ and the analytes were successively eluted with acetonitrile. After that, the eluates collected from the previous step were evaporated under a $\mathrm{N}_{2}$ stream to dryness at $40^{\circ} \mathrm{C}$. Then the dried residues were reconstituted with 125 $\mu \mathrm{L}$ of mobile phase and centrifuged at $15,000 \mathrm{rpm}$ for $7 \mathrm{~min}$ at room temperature and then filtered using syringe membrane filters $(13 \mathrm{~mm})$ kinesis to be ready for injection and analysis into the UPLC system.

2.5. Method Validation. The assay validation was carried out in accordance with guidance for bioanalytical method validation recommended by the FDA [24]. Method development and validation for the adopted bioanalytical chromatographic method in plasma samples include the demonstration of (1) selectivity; (2) calibration curve, linearity, and sensitivity; (3) accuracy and precision; (4) recovery; and (5) stability of the analytes in the spiked plasma samples.

2.5.1. Selectivity. The potential interferences from endogenous matrix components were investigated by evaluating ten different lots of human plasma as blank and at the LLOQ level of the spiked SF and DC. Drug-free plasma samples chromatograms were compared with those of the spiked plasma to ensure the absence of analytical interferences from endogenous substances present in plasma samples.

2.5.2. Calibration Curve, Linearity, and Sensitivity. Eightpoint calibration standard curves of SF and DC in plasma, ranging from 25 to $6400 \mathrm{ng} \cdot \mathrm{mL}^{-1}$ and 50 to $12800 \mathrm{ng} \cdot \mathrm{mL}^{-1}$, respectively, were prepared in triplicate for each run. The LLOQ is the lowest concentration in the standard calibration curve that back-calculates with good precision that does not exceed $20 \%$ of the CV and satisfactory accuracy which does not exceed $20 \%$ of the nominal concentration.

2.5.3. Accuracy and Precision. Accuracy, intraday precision, and interday precision values were determined by the analysis of spiked human plasma samples with five different concentrations for each of SF and DC, corresponding to the LLOQ, low, medium, high QC samples, and ULOQ three times on the same day and on three separate days. Accuracy was expressed as the $\%$ of deviation between the nominal and measured concentration (\% error). Precision was calculated as coefficient of variation \% (CV).

2.5.4. Recovery. The overall recovery of SF and DC from spiked human plasma was determined at the LLOQ, low, medium, high QC samples, and ULOQ. The ratio of the peak area response of extracted QC samples for SF or DC to that of the IS was compared to that of unextracted standards obtained by injecting the corresponding concentration of DC and IS in the mobile phase and analyzed in triplicate. The extraction recovery was computed as previously published $[12,26]$, using the ratio of the response and the assay concentration factor (500:125, since during SPE procedure $500 \mu \mathrm{L}$ spiked plasma samples was extracted, evaporated to dryness under a $\mathrm{N}_{2}$ stream at $40^{\circ} \mathrm{C}$, and then reconstituted with $125 \mu \mathrm{L}$ of the mobile phase), and was expressed as \% of the response of the calculated amount of SF or DC diluted in mobile phase and directly injected into the UPLC system, which corresponded to $100 \%$ recovery.

2.5.5. Stability of the Analytes in the Spiked Plasma Samples. Stability tests were carried out under various conditions simulating those that a real human plasma samples may be subjected to during routine analysis. Stability studies of SF and DC in human plasma included the following:

(a) Freeze and thaw stability after three freeze-thaw cycles of stored plasma samples; (b) bench-top stability of plasma samples after storage at RT for $48 \mathrm{~h}$; (c) long-term stability of plasma samples after storage at-80âŮęC for 6 months; stability of SF and DC stock solutions (d) kept in the refrigerator and (e) kept on bench; and processed sample stability (f) after the heating process for the frozen plasma samples $\left(60^{\circ} \mathrm{C}\right.$ for $\left.60 \mathrm{~min}\right)$ in addition to $(\mathrm{g})$ the stability of the dried extracts (after SPE procedure) at $-20^{\circ} \mathrm{C}$ for 6 days and (h) the stability of the reconstituted extracts in the mobile phase after being kept at $4^{\circ} \mathrm{C}$ for 4 days in the autosampler.

For each of the previously mentioned conditions, three series of LLOQ, LQ, MQ, HQ, and ULOQ spiked plasma samples were analyzed. The SF and DC concentrations in the analyzed plasma samples were compared to freshly made QC samples. For all of the previously mentioned stability studies, SF and DC in plasma samples were considered as stable if the stability sample results were within $15 \%$ of nominal concentrations according to the FDA guidelines for bioanalytical method validation [24].

\section{Results and Discussion}

3.1. Chromatographic Separation Conditions and Sample Extraction Procedure. The chromatographic separation of SF and DC was carried out using different HPLC columns and various mobile phases. The proper chromatographic separation was achieved on Waters ${ }^{\circledR}$ Acquity UPLC BEH $\mathrm{C}_{18}$ column $(2.1 \times 50 \mathrm{~mm}, 1.7 \mu \mathrm{m})$ using isocratic elution with a mobile phase of ammonium formate $(\mathrm{pH} 3.5 ; 5$ $\mathrm{mM})$ and acetonitrile $(60: 40 \mathrm{v} / \mathrm{v})$ pumped at a flow rate 0.2 $\mathrm{mL} \cdot \mathrm{min}^{-1}$. According to these chromatographic conditions, SF was eluted at $1.123 \mathrm{~min}$ while DC was eluted at $3.179 \mathrm{~min}$ with a perfect separation from plasma endogenous peaks as presented in Figure 2. The total run time is considered to be short which allows faster analysis of multiple samples during routine work using simple isocratic elution. Figure 2 represents the chromatograms of (a) drug-free human plasma; 


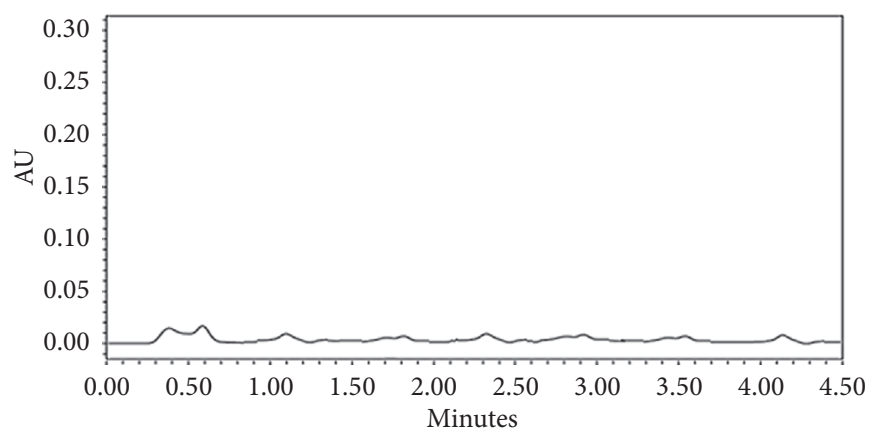

(a)

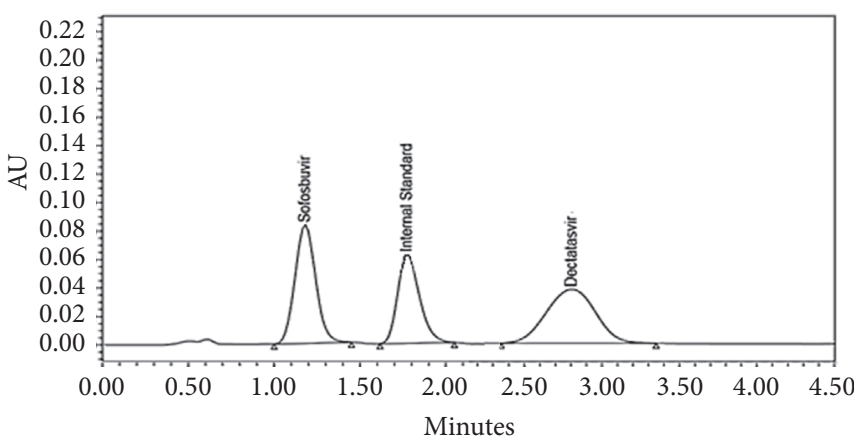

(b)

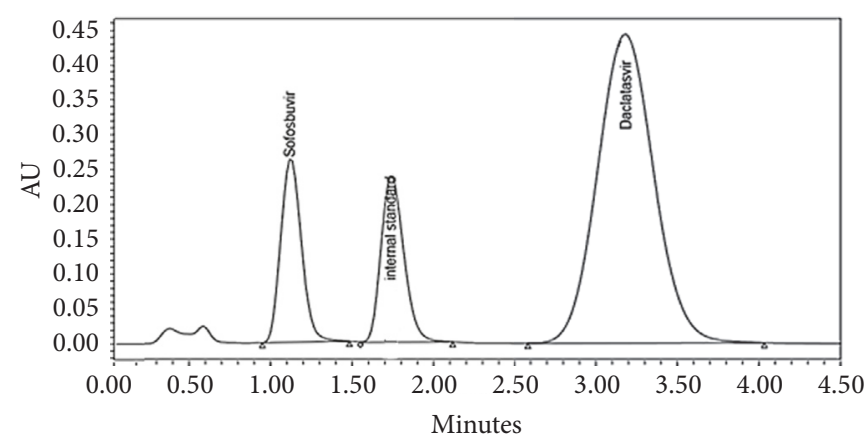

(c)

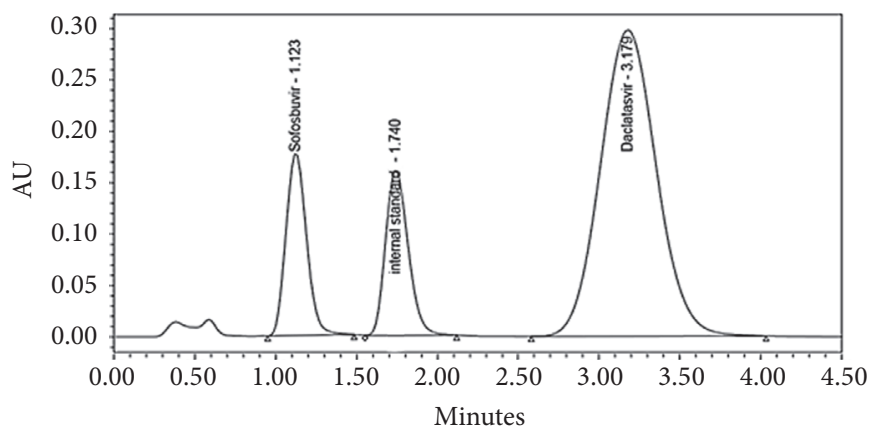

(d)

FIGURE 2: Typical UPLC chromatograms of (a) drug-free human plasma; (b) blank plasma spiked with SF and DC at LLOQ, (c) blank plasma spiked with SF and DC at ULOQ, and (d) plasma sample from a volunteer $0.5 \mathrm{~h}$ after administration of Darvoni ${ }^{\circledR}(400 \mathrm{mg}$ of SF/60 mg of DC).

(b) blank plasma spiked with SF and DC at LLOQ; (c) blank plasma spiked with SF and DC at ULOQ; and (d) plasma sample from a volunteer $0.5 \mathrm{~h}$ after administration of Darvoni $^{\circledR}$ (400 mg of SF/60 mg of DC).

A satisfactory drug recovery in sample extraction is crucial for the simultaneous estimation of SF and DC in human plasma at low concentration levels. Various extraction procedures were tried such as liquid-liquid extraction with different solvents and protein precipitation techniques, but they gave very low drug recovery which lead to significant interference from plasma peaks background. Deproteinization using acetonitrile was carried out due to the fact that SF and DC are 61-65\% [27] and 99\% [28] bound to human plasma proteins, respectively, followed by a neat SPE procedure employing Water 20-positions Extraction Manifold with
SPE cartridges (Sep-Pak ${ }^{\circledR}$ Vac $\mathrm{C}_{18}$ ) which was considered as a reliable and fast technique for determination of SF and DC in human plasma samples. This extraction strategy allowed the improvement of sample clean-up without lowering drug recovery leading to high and constant recovery of SF and DC from human plasma.

\subsection{Method Validation}

3.2.1. Selectivity. Plasma sample extraction and chromatographic separation procedures were carried out to obtain a selective simultaneous determination for SF and DC. Various lots of blank human plasma from different sources were carefully evaluated for interference from endogenous matrix components. A typical chromatogram of blank human 
plasma is illustrated in Figure 2(a) which does not present any significant interfering endogenous peaks from human plasma at the retention times of SF, DC, or IS. The absence of any analytical interference was also assured using the peak purity checker system and matching with the library of the Empower ${ }^{\circledR}$ software.

3.2.2. Calibration Curve, Linearity, and Sensitivity. Two calibration standard curves of SF and DC in plasma, ranging from 25 to $6400 \mathrm{ng} . \mathrm{mL}^{-1}$ and 50 to $12800 \mathrm{ng} \cdot \mathrm{mL}^{-1}$, respectively, were prepared in triplicate for each run. The calibration plots showed linearity over the previously mentioned concentration ranges and the determination coefficient $\left(r^{2}\right)$ was not less than 0.998 . The LLOQ is the lowest concentration in the standard calibration curve that back-calculates with good precision that does not exceed $20 \%$ of the CV and good accuracy within $20 \%$ of the nominal concentration. The LLOQ of SF and DC was 25 and 50 ng. $\mathrm{mL}^{-1}$, respectively. A typical chromatogram for a spiked plasma sample containing the LLOQ for both SF and DC is presented in Figure 2(b). This figure presents satisfactory sensitivity for the routine analysis of human plasma samples in clinical application of therapeutic drug monitoring.

3.2.3. Accuracy and Precision. Data results for accuracy (expressed as \% bias $=$ [measured concentration - nominal concentration] / nominal concentration $\times 100$ ) and precision (expressed as \% CV) presented in Table 2 were less than $15 \%$ from the nominal concentrations and $<20 \%$ for LLOQ, according to FDA guidelines [24]. These results show that the adopted chromatographic method provides a high degree of accuracy and reproducibility.

3.2.4. Extraction Recovery. The average of \% extraction recovery for SF and DC in their respective concentration ranges varied from 90.0 to $107.2 \%$ and 93.1 to $108.0 \%$ for SF and DC, respectively, with \% CV values ranging from 1.2 to 3.5 $\%$ and 1.1 to $3.6 \%$ for SF and DC, respectively, as presented in Table 2. These data results demonstrate that the extraction procedure for human plasma samples produces clean extracts and good recovery to reach to satisfactory sensitivity for the analysis.

3.2.5. Stability Studies. The stability of SF and DC in human plasma samples at five levels (LLOQ, LQ, MQ, HQ, and ULOQ) was investigated under the following conditions that the common and routine clinical samples are usually subjected to [29-31]: (a) after three freeze-thaw cycles (24 hours at $-80^{\circ} \mathrm{C}$ to room temperature) on plasma samples spiked with SF and DC, the recovered concentrations of SF and DC were very similar to those of freshly spiked plasma samples. In addition, no decomposition products of SF or DC were detected during (b) short-term storage $(48 \mathrm{~h})$ of plasma samples at RT and (c) long-term storage at $-80^{\circ} \mathrm{C}$ for 6 months as illustrated in Table 3 which confirms the high stability of both SF and DC in human plasma samples both at $\mathrm{RT}$ and at $-80^{\circ} \mathrm{C}$. Stock solution stability for SF and DC was also assessed. The stability of the standard solutions kept in refrigerator and those kept on bench was compared to freshly prepared standard solutions. It was found that solutions kept in (d) refrigerator are stable up to 10 days while those kept on (e) bench are stable for only 5 days. Moreover, the processed sample stability for SF and DC after the (f) heating process for the frozen plasma samples $\left(60^{\circ} \mathrm{C}\right.$ for $\left.60 \mathrm{~min}\right)$ in addition to the stability of the (g) dried extracts (after SPE procedure) at $-20^{\circ} \mathrm{C}$ for 6 days and in the processed plasma samples (h) reconstituted in the mobile phase after being kept at $4^{\circ} \mathrm{C}$ for 4 days in the autosampler was also tested. After the heating process for the frozen plasma samples $\left(60^{\circ} \mathrm{C}\right.$ for $\left.60 \mathrm{~min}\right)$ and after 6 days storage of the dried extracts at $-20^{\circ} \mathrm{C}$ or 4 days storage for the reconstituted extracts in the autosampler at $4^{\circ} \mathrm{C}$, concentrations of the processed plasma samples were within $\pm 15 \%$ of their nominal concentrations and $<20 \%$ for LLOQ as presented in Table 3, indicating that both drugs are stable under the stated conditions to which routine plasma samples are subjected.

3.3. Application of the Adopted Method to the Plasma Samples of Healthy Volunteers. Concentrations of SF and DC were estimated using the adopted UPLC-PDA method in the plasma samples obtained from three healthy male volunteers after the oral intake of one Darvoni ${ }^{\circledR}$ tablet coformulated with $400 \mathrm{mg}$ of SF and $60 \mathrm{mg}$ of DC. To confirm the clinical application of the suggested method, a typical UPLC chromatogram of a plasma sample obtained from one of the volunteers after $0.5 \mathrm{~h}$ from the oral intake of one Darvoni ${ }^{\circledR}$ tablet is presented in Figure 2(d). The shown chromatogram assures satisfactory and good clinical application of the adopted chromatographic method during routine therapeutic drug monitoring. The good recovery of SF produced by the application of the proposed UPLC-PDA method makes no need to quantify the main metabolite of SF (GS331007).

\section{Conclusion}

A rapid, accurate, precise, sensitive, and selective UPLCPDA method was developed for simultaneous quantification of SF and DC in plasma samples has been adopted in this work for the first time. The developed method had been validated according to FDA guidelines for bioanalytical method validation. The method applicability was confirmed by the analysis of plasma samples of three healthy volunteers after the oral intake of coformulated Darvoni ${ }^{\circledR}$ tablet. So far, the previously published analytical methods developed for pharmacokinetic investigations of SF and DC were all based on costly LC-MS/MS equipment after the oral intake of two tablets for each drug, which decreased the feasibility of the routine analysis of SF and DC. The adopted UPLCUV method is considered to be greatly applicable for the routine TDM of SF and DC in plasma at conventional clinical laboratories where LC-MS/MS equipment is not present. The suggested method will be suitable for standard clinical laboratories that do not possess LC-MS/MS equipment. With respect to large-scale pharmacokinetic analysis, the proposed 
TABle 2

(a) Accuracy, intraday, and interday precision and \% extraction recovery for SF and DC in their QC samples in human plasma $(\mathrm{n}=6)$

\begin{tabular}{|c|c|c|c|c|c|}
\hline \multirow[b]{2}{*}{$\begin{array}{l}\text { Nominal } \\
\text { Concentration } \\
\left(\text { ng.mL } \mathrm{m}^{-1}\right)\end{array}$} & \multicolumn{4}{|c|}{ SF } & \multirow[b]{2}{*}{$\begin{array}{c}\% \text { Extraction recovery } \\
\pm \% \mathrm{CV}\end{array}$} \\
\hline & $\begin{array}{l}\text { Average of the } \\
\text { measured } \\
\text { concentration } \\
\left(\text { ng.ml } \mathrm{ml}^{-1}\right)\end{array}$ & $\begin{array}{l}\text { Accuracy } \\
\text { (\% Bias) }\end{array}$ & $\begin{array}{l}\text { Intra-day } \\
\text { precision } \\
(\% \mathrm{CV})\end{array}$ & $\begin{array}{l}\text { Inter-day } \\
\text { precision } \\
(\% \mathrm{CV})\end{array}$ & \\
\hline 25 & 24 & -4.0 & 9.6 & 8.6 & $96.0 \pm 1.2$ \\
\hline 50 & 45 & -10.0 & 4.6 & 5.1 & $90.0 \pm 3.5$ \\
\hline 400 & 425 & 6.3 & 5.2 & 9.3 & $106.3 \pm 1.3$ \\
\hline 3200 & 3430 & 7.2 & 3.9 & 7.4 & $107.2 \pm 2.8$ \\
\hline 6400 & 6123 & -4.3 & 3.8 & 6.1 & $95.7 \pm 1.5$ \\
\hline \multicolumn{6}{|c|}{ DC } \\
\hline $\begin{array}{l}\text { Nominal } \\
\text { Concentration } \\
\left(\text { ng. } \mathrm{mL}^{-1}\right)\end{array}$ & $\begin{array}{l}\text { Average of the } \\
\text { measured } \\
\text { concentration } \\
\left(\text { ng.ml } \mathrm{ml}^{-1}\right)\end{array}$ & Accuracy & $\begin{array}{l}\text { Intra-day } \\
\text { precision }\end{array}$ & $\begin{array}{l}\text { Inter-day } \\
\text { precision }\end{array}$ & $\begin{array}{c}\% \text { Extraction recovery } \\
\pm \% \mathrm{CV}\end{array}$ \\
\hline 50 & 54 & 8.0 & 6.5 & 3.7 & $108.0 \pm 2.3$ \\
\hline 100 & 95 & -5.0 & 9.2 & 9.1 & $95.0 \pm 1.7$ \\
\hline 1600 & 1490 & -6.9 & 4.7 & 7.5 & $93.1 \pm 1.1$ \\
\hline 6400 & 6690 & 4.5 & 5.4 & 6.4 & $104.5 \pm 2.0$ \\
\hline 12800 & 12357 & -3.5 & 2.8 & 8.2 & $96.5 \pm 3.6$ \\
\hline
\end{tabular}

(b) Accuracy, intraday, and interday precision and \% extraction recovery for SF and DC in their QC samples in human plasma (n=6)

\begin{tabular}{|c|c|c|c|c|c|}
\hline \multirow{2}{*}{$\begin{array}{l}\text { Nominal } \\
\text { Concentration } \\
\left(\text { ng.mL } \mathrm{mL}^{-1}\right)\end{array}$} & \multicolumn{5}{|c|}{ SF } \\
\hline & $\begin{array}{l}\text { Average of the measured } \\
\text { concentration } \\
\left(\text { ng. } \mathrm{ml}^{-1}\right)\end{array}$ & $\begin{array}{l}\text { Accuracy } \\
\text { (\% Bias) }\end{array}$ & $\begin{array}{l}\text { Intra-day precision } \\
(\% \mathrm{CV})\end{array}$ & $\begin{array}{l}\text { Inter-day precision } \\
(\% \mathrm{CV})\end{array}$ & $\begin{array}{c}\% \text { Extraction recovery } \\
\pm \% \mathrm{CV}\end{array}$ \\
\hline 25 & 24 & -4.0 & 9.6 & 8.6 & $96.0 \pm 1.2$ \\
\hline 50 & 45 & -10.0 & 4.6 & 5.1 & $90.0 \pm 3.5$ \\
\hline 400 & 425 & 6.3 & 5.2 & 9.3 & $106.3 \pm 1.3$ \\
\hline 3200 & 3430 & 7.2 & 3.9 & 7.4 & $107.2 \pm 2.8$ \\
\hline 6400 & 6123 & -4.3 & 3.8 & 6.1 & $95.7 \pm 1.5$ \\
\hline \multirow{2}{*}{$\begin{array}{l}\text { Nominal } \\
\text { Concentration } \\
\left(\text { ng. } \mathrm{mL}^{-1}\right)\end{array}$} & \multicolumn{5}{|c|}{ DC } \\
\hline & $\begin{array}{l}\text { Average of the measured } \\
\text { concentration } \\
\left(\text { ng.ml }{ }^{-1}\right)\end{array}$ & Accuracy & Intra-day precision & Inter-day precision & $\begin{array}{c}\% \text { Extraction recovery } \\
\pm \% \mathrm{CV}\end{array}$ \\
\hline 50 & 54 & 8.0 & 6.5 & 3.7 & $108.0 \pm 2.3$ \\
\hline 100 & 95 & -5.0 & 9.2 & 9.1 & $95.0 \pm 1.7$ \\
\hline 1600 & 1490 & -6.9 & 4.7 & 7.5 & $93.1 \pm 1.1$ \\
\hline 6400 & 6690 & 4.5 & 5.4 & 6.4 & $104.5 \pm 2.0$ \\
\hline 12800 & 12357 & -3.5 & 2.8 & 8.2 & $96.5 \pm 3.6$ \\
\hline
\end{tabular}

method will be a satisfactory, simple, cheap, fast, and easier to set up alternative UPLC chromatographic method coupled with DAD. Stability studies of SF and DC under various common conditions to which both drugs may be subjected to during sample handling and analysis through routine TDM process illustrated that both drug concentrations remained approximately unchanged in plasma, in their stock solutions, and in processed plasma samples under different storage conditions. All in all, the adopted UPLC-DAD technique and the data results of the stability studies analyses could be valuable for dosing both drugs and appropriately dealing with their plasma samples both in routine clinical application and in TDM. This clinical application gave the opportunity to the optimization of the drug treatment which can improve the life quality and increase the therapy efficacy itself. It can lead also to a cost saving outcome, reducing side effects, and consequently a better clinical cost for patient's care. 
TABLE 3: Stability of SF and DC in plasma samples under several storage conditions.

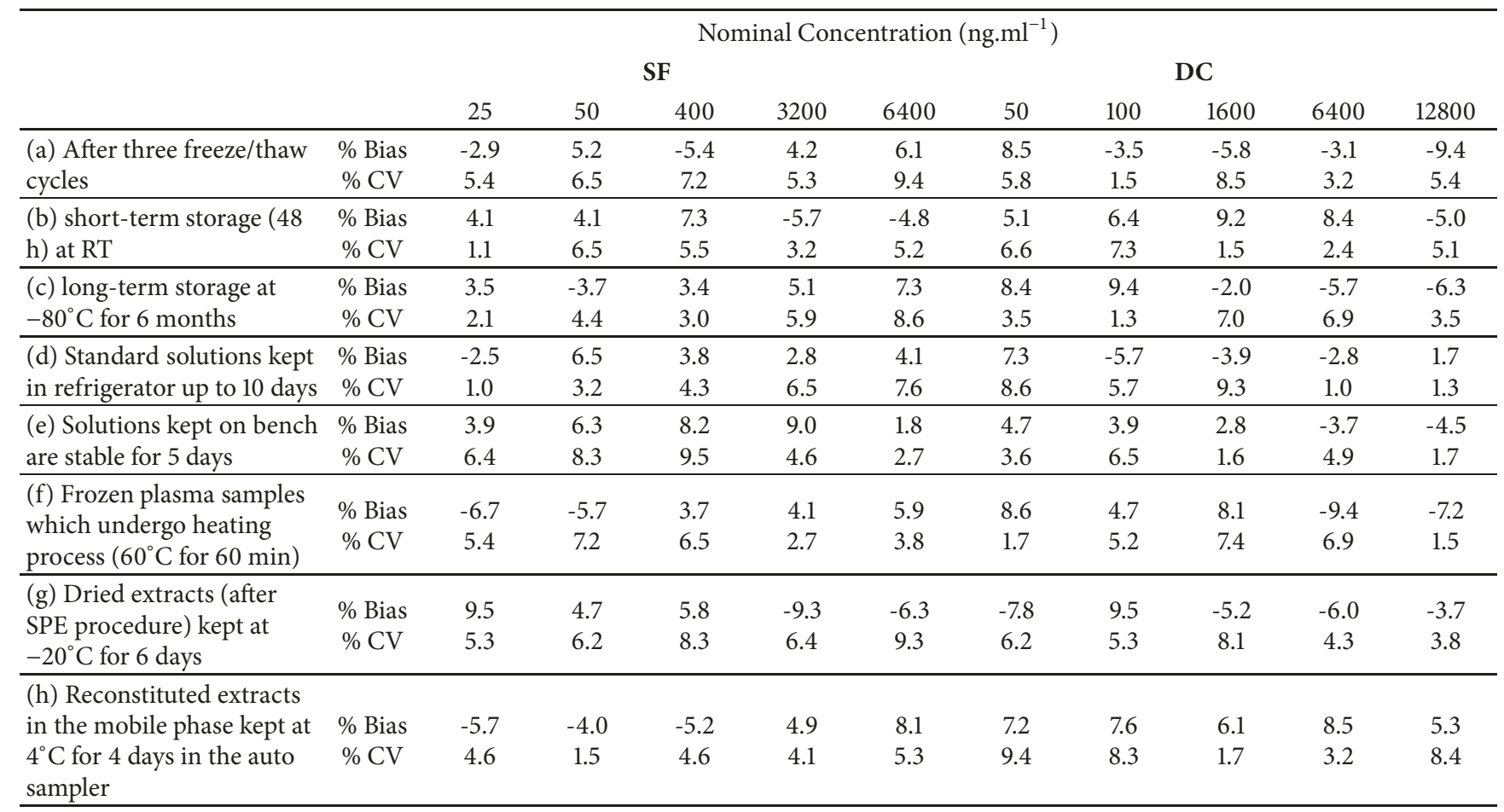

\section{Data Availability}

The data used to support the findings of this study are included within the article.

\section{Disclosure}

The authors receive no specific grant from funding agencies in the public, commercial, or not-for-profit sectors to develop this study.

\section{Conflicts of Interest}

The authors declare that there are no conflicts of interest regarding the publication of this paper.

\section{References}

[1] Y. A. Mohamoud, G. R. Mumtaz, S. Riome, D. Miller, and L. J. Abu-Raddad, "The epidemiology of hepatitis C virus in Egypt: a systematic review and data synthesis," BMC Infectious Diseases, vol. 13, no. 1, article 288, 2013.

[2] M. G. Ghany, D. B. Strader, D. L. Thomas, and L. B. Seeff, "Diagnosis, management, and treatment of hepatitis C: an update," Hepatology, vol. 49, no. 4, pp. 1335-1374, 2009.

[3] B. J. Kirby, W. T. Symonds, B. P. Kearney, and A. A. Mathias, "Pharmacokinetic, Pharmacodynamic, and Drug-Interaction Profile of the Hepatitis C Virus NS5B Polymerase Inhibitor Sofosbuvir," Clinical Pharmacokinetics, vol. 54, no. 7, pp. 677690, 2015.

[4] https://pubchem.ncbi.nlm.nih.gov/compound/sofosbuvir.
[5] G. Bertino, A. Ardiri, M. Proiti et al., "Chronic hepatitis C: this and the new era of treatment," World Journal of Hepatology, vol. 8, no. 2, pp. 92-106, 2016.

[6] https://pubchem.ncbi.nlm.nih.gov/compound/Daclatasvir.

[7] F. Poordad, E. R. Schiff, J. M. Vierling et al., "Daclatasvir with sofosbuvir and ribavirin for hepatitis $\mathrm{C}$ virus infection with advanced cirrhosis or post-liver transplantation recurrence," Hepatology, vol. 63, no. 5, pp. 1493-1505, 2016.

[8] A. F. Luetkemeyer, C. McDonald, M. Ramgopal, S. Noviello, R. Bhore, and P. Ackerman, "12 Weeks of Daclatasvir in Combination with Sofosbuvir for HIV-HCV Coinfection (ALLY-2 Study): Efficacy and Safety by HIV Combination Antiretroviral Regimens," Clinical Infectious Diseases, vol. 62, no. 12, pp. 14891496, 2016.

[9] https://pubchem.ncbi.nlm.nih.gov/compound/Ledipasvir.

[10] J. Vionnet, A.-C. Saouli, M. Pascual et al., "Therapeutic drug monitoring for sofosbuvir and daclatasvir in transplant recipients with chronic hepatitis C and advanced renal disease," Journal of Hepatology, vol. 65, no. 5, pp. 1063-1065, 2016.

[11] S. Burgess, N. Partovi, E. M. Yoshida, S. R. Erb, V. M. Azalgara, and T. Hussaini, "Drug Interactions With Direct-Acting Antivirals for Hepatitis C: Implications for HIV and Transplant Patients," Annals of Pharmacotherapy, vol. 49, no. 6, pp. 674-687, 2015.

[12] G. Nannetti, L. Messa, M. Celegato et al., "Development and validation of a simple and robust HPLC method with UV detection for quantification of the hepatitis $\mathrm{C}$ virus inhibitor daclatasvir in human plasma," Journal of Pharmaceutical and Biomedical Analysis, vol. 134, pp. 275-281, 2017.

[13] S. Miraghaei, B. Mohammadi, A. Babaei, S. Keshavarz, and G. Bahrami, "Development and validation of a new HPLCDAD method for quantification of sofosbuvir in human serum and its comparison with LC-MS/MS technique: Application to 
a bioequivalence study," Journal of Chromatography B, vol. 1063, pp. 118-122, 2017.

[14] S. Madhavi and A. P. Rani, "Bioanalytical method development and validation for the determination of sofosbuvir from human plasma," International Journal of Pharmacy and Pharmaceutical Sciences, vol. 9, no. 3, pp. 35-41, 2017.

[15] D. W. Zidan, W. S. Hassan, M. S. Elmasry, and A. A. Shalaby, "Investigation of anti-Hepatitis $\mathrm{C}$ virus, sofosbuvir and daclatasvir, in pure form, human plasma and human urine using micellar monolithic HPLC-UV method and application to pharmacokinetic study," Journal of Chromatography B, vol. 1086, pp. 73-81, 2018.

[16] S. Notari, M. Tempestilli, G. Fabbri et al., "UPLC-MS/MS method for the simultaneous quantification of sofosbuvir, sofosbuvir metabolite (GS-331007) and daclatasvir in plasma of HIV/HCV co-infected patients," Journal of Chromatography B, vol. 1073, pp. 183-190, 2018.

[17] O. M. Abdallah, A. M. Abdel-Megied, and A. S. Gouda, "Development and validation of LC-MS/MS method for simultaneous determination of sofosbuvir and daclatasvir in human Plasma: Application to pharmacokinetic study," Biomedical Chromatography, no. 1, pp. 1-9, 2018.

[18] A. Ariaudo, F. Favata, A. De Nicolò et al., "A UHPLC-MS/MS method for the quantification of direct antiviral agents simeprevir, daclatasvir, ledipasvir, sofosbuvir/GS-331007, dasabuvir, ombitasvir and paritaprevir, together with ritonavir, in human plasma," Journal of Pharmaceutical and Biomedical Analysis, vol. 125, pp. 369-375, 2016.

[19] M. R. Rezk, E. B. Basalious, and M. E. Amin, "Novel and sensitive UPLC-MS/MS method for quantification of sofosbuvir in human plasma: application to a bioequivalence study," Biomedical Chromatography, vol. 30, no. 9, pp. 1354-1362, 2016.

[20] M. R. Rezk, E. R. Bendas, E. B. Basalious, and I. A. Karim, "Development and validation of sensitive and rapid UPLCMS/MS method for quantitative determination of daclatasvir in human plasma: Application to a bioequivalence study," Journal of Pharmaceutical and Biomedical Analysis, vol. 128, pp. 61-66, 2016.

[21] H. Jiang, H. Kandoussi, J. Zeng et al., "Multiplexed LC-MS/MS method for the simultaneous quantitation of three novel hepatitis $\mathrm{C}$ antivirals, daclatasvir, asunaprevir, and beclabuvir in human plasma," Journal of Pharmaceutical and Biomedical Analysis, vol. 107, pp. 409-418, 2015.

[22] L. Qu, W. Wang, D. Zeng, Y. Lu, and Z. Yin, "Quantitative performance of online SPE-LC coupled to Q-Exactive for the analysis of sofosbuvir in human plasma," RSC Advances, vol. 5, no. 119, pp. 98269-98277, 2015.

[23] M. R. Rezk, E. B. Basalious, and I. A. Karim, "Development of a sensitive UPLC-ESI-MS/MS method for quantification of sofosbuvir and its metabolite, GS-331007, in human plasma: Application to a bioequivalence study," Journal of Pharmaceutical and Biomedical Analysis, vol. 114, pp. 97-104, 2015.

[24] FDA, "Guidance for Industry: Bio analytical Method Validation,” 2013, https://www.fda.gov/downloads/drugs/guidances/ ucm070107.Pdf.

[25] "European Medicines Agency Daklinza: Assessment Report, 2014," http://www.ema.europa.eu/docs/en_GB/document_library/ EPAR_Public_assessment_report/human/003768/WC500172849 .pdf.

[26] A. Loregian, S. Pagni, E. Ballarin, E. Sinigalia, S. G. Parisi, and G. Palù, "Simple determination of the HIV protease inhibitor atazanavir in human plasma by high-performance liquid chromatography with UV detection," Journal of Pharmaceutical and Biomedical Analysis, vol. 42, no. 4, pp. 500-505, 2006.

[27] E. Cholongitas and G. V. Papatheodoridis, "Sofosbuvir: a novel oral agent for chronic hepatitis C," Annals of Gastroenterology, vol. 27, pp. 331-337, 2014.

[28] R. E. Nettles, M. Gao, M. Bifano et al., "Multiple ascending dose study of BMS-790052, a nonstructural protein 5A replication complex inhibitor, in patients infected with hepatitis $C$ virus genotype 1," Hepatology, vol. 54, no. 6, pp. 1956-1965, 2011.

[29] N. F. Al-Tannak, "UHPLC-UV method for simultaneous determination of perindopril arginine and indapamide hemihydrate in combined dosage form: a stability-indicating assay method," Scientia Pharmaceutica, vol. 86, p. 7, 2018.

[30] N. F. Al-Tannak and A. Hemdan, "UHPLC-ESI-QToF analysis of trandolapril and verapamil hydrochloride in dosage form and spiked human plasma using solid phase extraction: stability indicating assay method," Current Pharmaceutical Analysis, vol. 14, no. 6, pp. 595-603, 2018.

[31] S. A. Mohammed, M. S. Eissa, and H. M. Ahmed, "Simple protein precipitation extraction technique followed by validated chromatographic method for linezolid analysis in real human plasma samples to study its pharmacokinetics," Journal of Chromatography B, vol. 1043, pp. 235-240, 2017. 

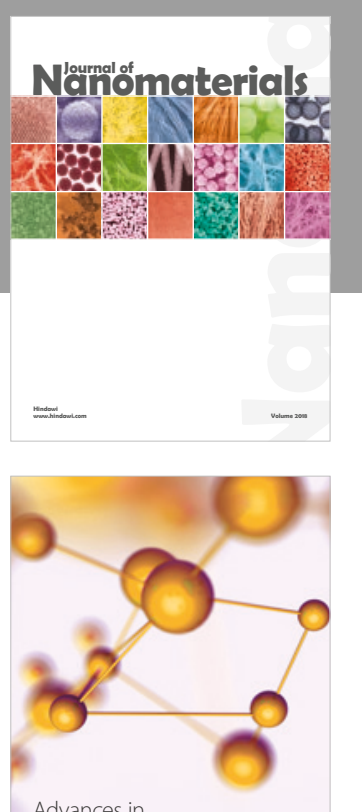

Physical Chemistry
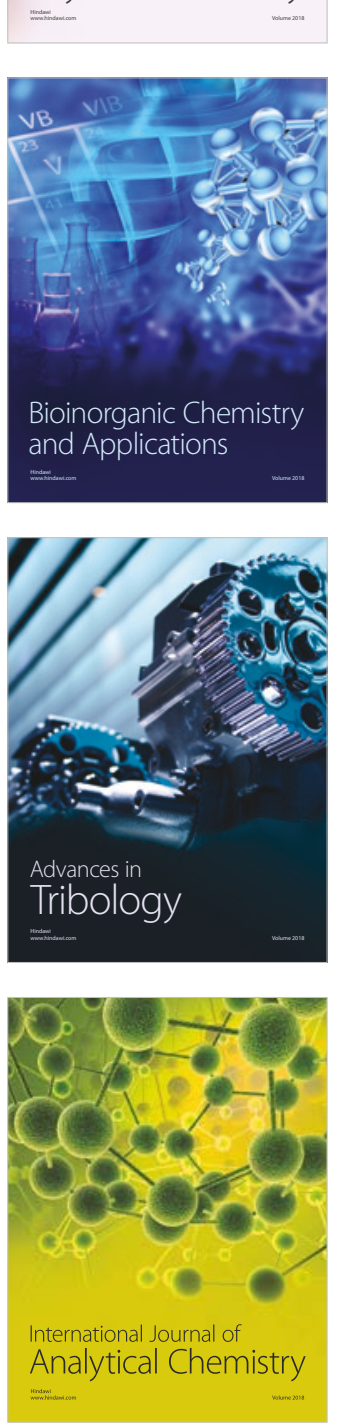

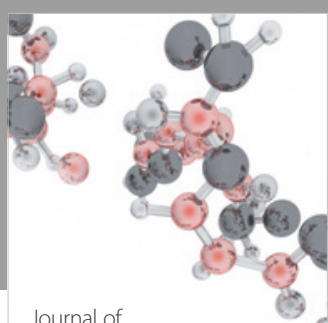

Analytical Methods

in Chemistry

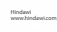

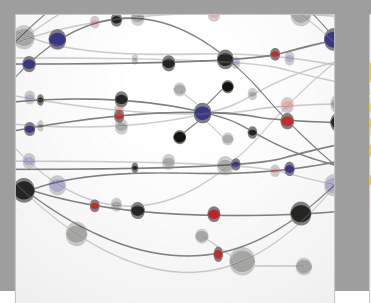

The Scientific World Journal

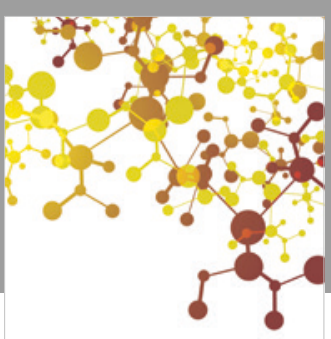

Journal of

Applied Chemistry
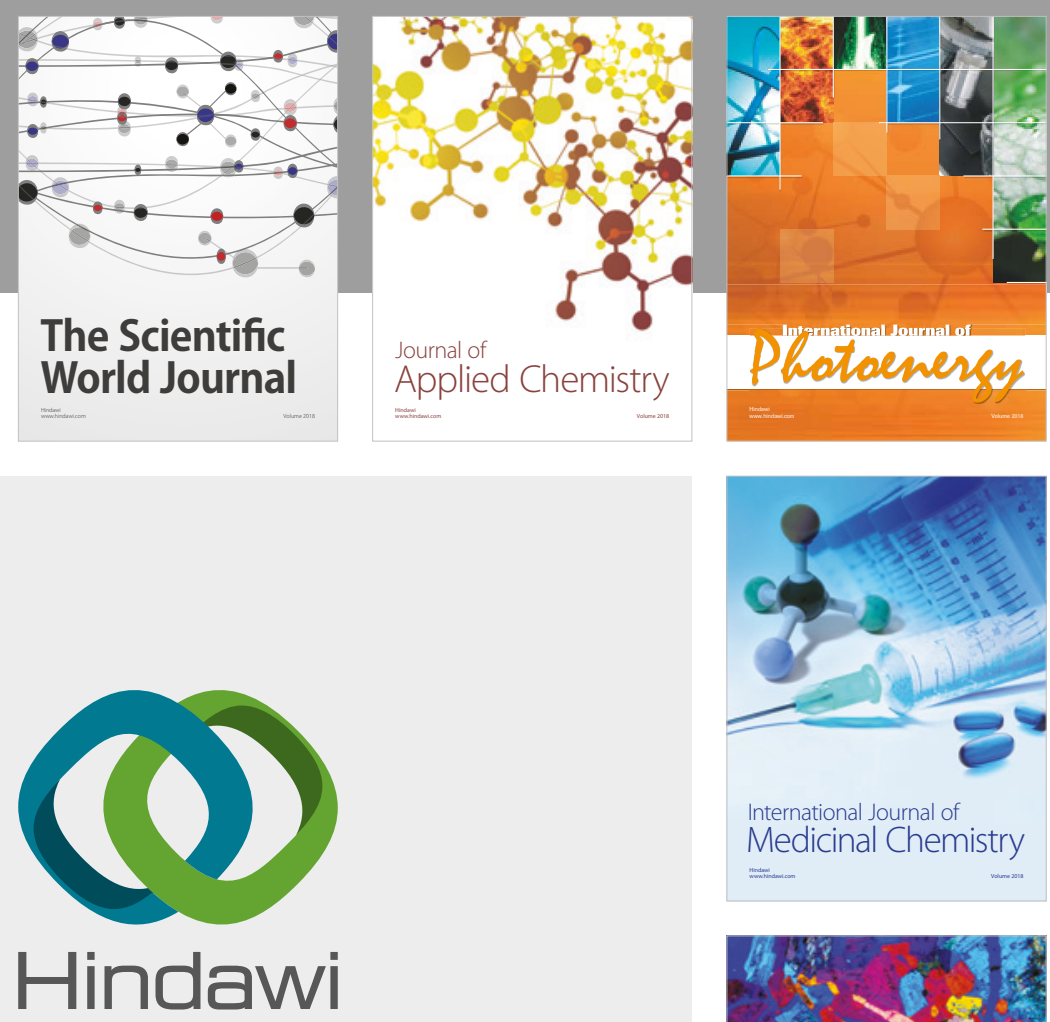

Submit your manuscripts at

www.hindawi.com
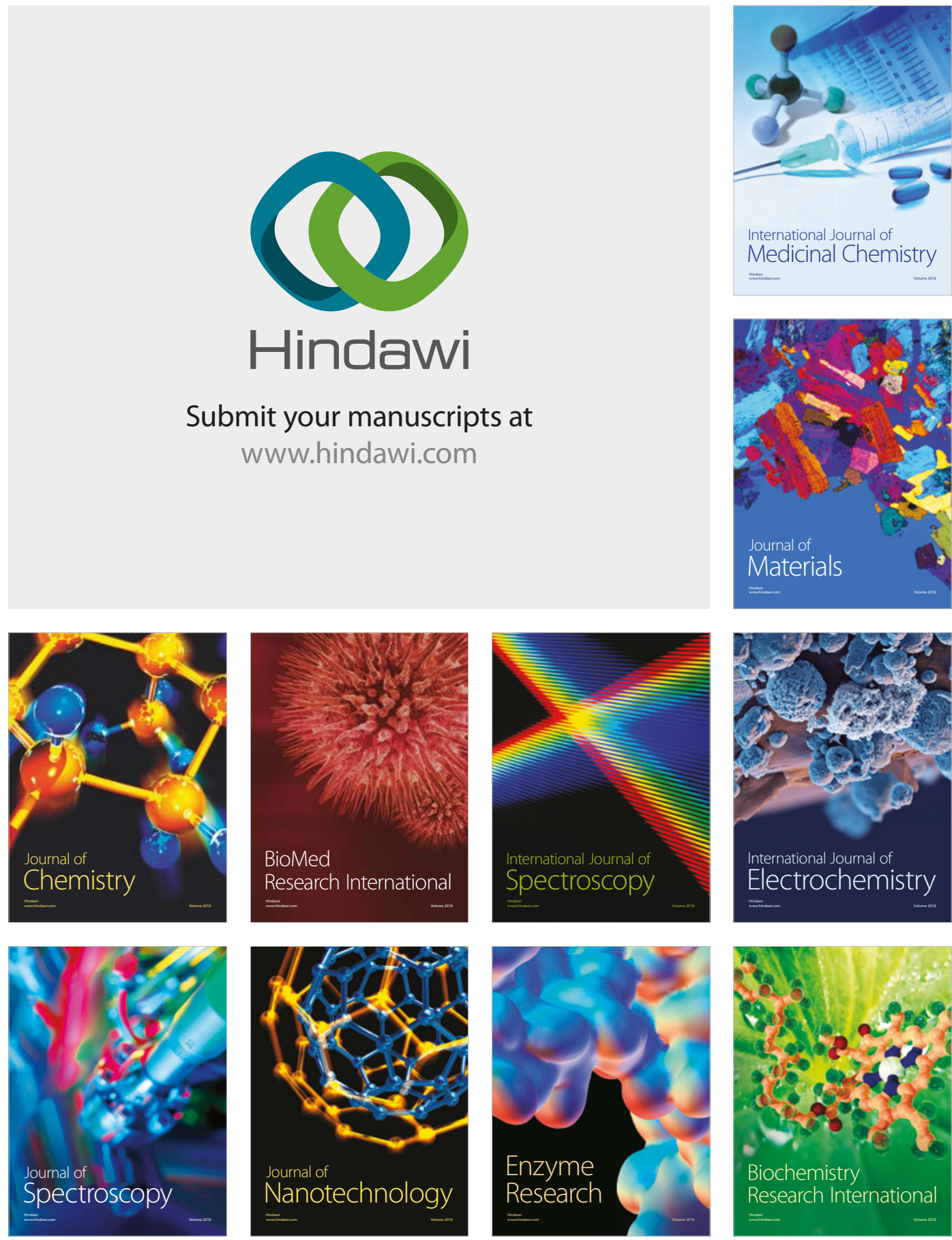
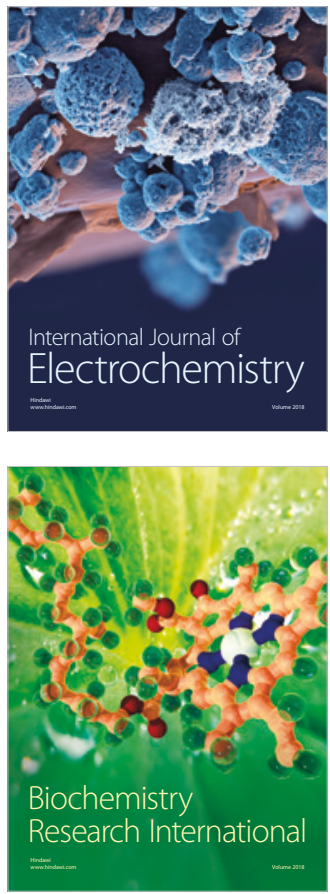